\title{
Does Cyclic Stress Play a Role in Highly Crosslinked Polyethylene Oxidation?
}

\author{
Francisco Medel PhD, Steven Kurtz PhD, \\ Daniel MacDonald MS, Francisco Javier Pascual MS, \\ José Antonio Puértolas PhD
}

Published online: 28 January 2015

(C) The Association of Bone and Joint Surgeons( 2015
Questions/purposes In our pilot study, we asked: (1) Does cyclic stress induced by wear or (2) by cyclic compression loading increase oxidation and crystallinity of remelted HXLPE? (3) Does oxidative aging reduce the wear resistance of remelted HXLPE?

Methods Remelted and annealed HXLPE prisms $(\mathrm{n}=1$ per test condition) were tested in a wear simulator for 500,000 cycles. After wear testing, some samples were subjected to accelerated aging and then wear-tested again. Wear track volumes were characterized by confocal microscopy. Thin films $(200-\mu \mathrm{m}$ thick) were microtomed from wear prisms and then used for Fourier transform infrared spectroscopy oxidation and crystallinity assessments. Remelted HXLPE compression cylinders $(n=1$ per test condition) were subjected to fatigue experiments and similar oxidation characterization.

Results Remelted HXLPE qualitatively showed low oxidation indices $(\leq 1)$ when subjected either to cyclic loading or aging alone. However, oxidation levels almost doubled in near-surface regions when remelted HXLPE samples underwent consecutive cyclic loading, artificial aging, and cyclic loading steps. The type of loading (wear versus compression fatigue) appeared to not affect the

\author{
F. J. Pascual \\ Centro Universitario de la Defensa, Academia General Militar, \\ Zaragoza, Spain
}

F. J. Pascual, J. A. Puértolas

Department of Materials Science and Technology-EINA, Instituto de Investigación en Ingeniería de Aragón (I3A), Universidad de Zaragoza, Zaragoza, Spain
S. Kurtz, D. MacDonald

Implant Research Center, School of Biomedical Engineering, Science, and Health Systems, Drexel University, Philadelphia, PA, USA 
oxidation behavior in the studied conditions. Annealed HXLPE showed higher oxidation (oxidation index $>3$ ) than remelted HXLPE and delamination wear. No delamination wear was observed in remelted HXLPE in agreement with its comparatively low oxidation levels (oxidation index $<3$ ).

Conclusions With the numbers available in our pilot study, the findings suggest that cyclic stress arising from a wear process or from cyclic compression may trigger the loss of oxidative stability of remelted HXLPE and contribute to synergistically accelerate its progression. Further studies of the effect of cyclic stress on oxidation of remelted HXLPE are needed.

Clinical Relevance Retrieval studies are warranted to determine the natural history of the in vivo oxidation and wear behavior of first-generation, remelted HXLPE.

\section{Introduction}

Minimizing the impact of oxidation on ultrahigh-molecular-weight polyethylene (UHMWPE) components is important for preserving their mechanical integrity while in vivo [3, 6, 26]. Gamma radiation sterilization of UHMWPE implants was recognized to result in both free radicals and crosslinking [26]. Free radicals are precursors of oxidation, which may compromise the mechanical integrity of the implant in the long term, whereas crosslinking has a direct relationship to wear reduction. To simultaneously address wear and oxidation resistance, modern, first-generation, highly crosslinked polyethylenes (HXLPEs) were developed and clinically introduced in 1998 [17, 21]. Historically, heavy-dose (1000 kGy) irradiated UHMWPE was first clinically introduced by Oonishi and colleagues in the 1970s with promising results, but this material was not commercially available [10, 23]. As opposed to the material introduced by Oonishi and coworkers, modern first-generation HXLPEs are produced by radiation crosslinking up to a dose of $100 \mathrm{kGy}$ with subsequent thermal stabilization. Different postirradiation thermal stabilization strategies are used to eliminate or at least reduce radiation-induced free radicals in HXLPE. In brief, these strategies can be classified as annealing or remelting (when the stabilization is carried out below or above the melting temperature of the polymer, respectively) [19, 30]. Annealing treatments are generally less aggressive to the original crystalline microstructure, and, therefore, the prethermal stabilization mechanical properties are largely preserved [13]. However, annealing stabilization leaves residual (measurable) free radicals, and, in this sense, researchers soon found evidence that annealed HXLPE implants oxidized in vivo [11, 12, 15].
Remelting treatments, on the other hand, yield no detectable free radicals, but it is at the expense of modification of the original crystallinity and, therefore, reduction in certain mechanical properties occurs such as fatigue and fracture resistance [19, 25].

Although remelted HXLPEs were initially considered oxidatively stable because of the absence of free radicals on production, there is now growing evidence that remelted retrievals are not completely stable in vivo. Muratoglu and colleagues confirmed ex vivo stability loss of remelted retrievals [22]. In their study, although all retrievals showed minimal oxidation at explantation, oxidation was observed to increase during shelf storage and long-term exposure of the retrievals to air. Likewise, other retrieval programs have reported evidence of measurable oxidation levels in remelted HXLPE retrievals after short or intermediate implantation times $[8,9,16]$. The mechanism of in vivo oxidation for remelted HXLPEs remains poorly understood. However, two potential mechanisms have been proposed: the action of biologic prooxidants such as squalene [24] and physiologic, cyclic loading. Squalene is an unsaturated lipid present in the synovial fluid that, through reaction with oxygen, may have the potential of generating free radicals in UHMWPE. Cyclic loading, on the other hand, is presumed to introduce enough mechanical energy to break molecular chains within the polymer, thus also creating free radicals.

In our pilot study, we asked: (1) Does cyclic stress induced by wear or (2) by cyclic compression loading increase oxidation and crystallinity of remelted HXLPE? (3) Does oxidative aging reduce the wear resistance of remelted HXLPE?

\section{Materials and Methods}

\section{Materials}

Compression-molded GUR 1050 (Orthoplastics Ltd, Lancashire, UK) was used as raw material. Prismatic preforms (approximately $16 \mathrm{~mm}$ thick) were machined and subjected to electron beam irradiation in air to a nominal dose of $50 \mathrm{kGy}$. After irradiation, crosslinked polyethylene (HXLPE) prisms underwent a 2-hour thermal stabilization treatment in vacuum, either below the melting temperature (annealing at $130^{\circ} \mathrm{C}$ ) or above it (remelting at $150^{\circ} \mathrm{C}$ ). Wear samples were then machined to their final dimensions of $50 \times 50 \times 12 \mathrm{~mm}^{3}$, thus removing the oxidized surface layer present in the preforms. In addition, compression cylinders ( $9 \mathrm{~mm}$ long, $6 \mathrm{~mm}$ in diameter; $\mathrm{L} / \mathrm{D}=1.5$ ) were machined from remelted HXLPE prisms for compressive fatigue experiments. 


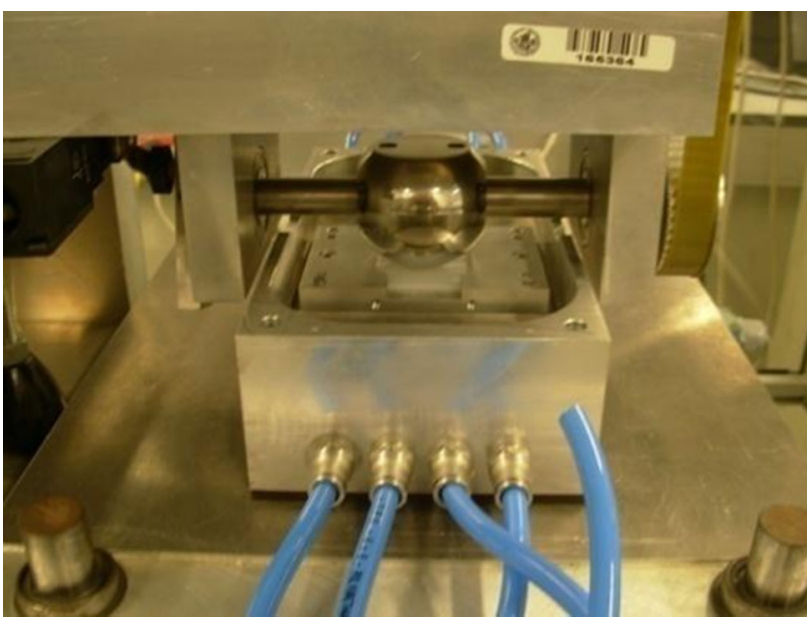

Fig. 1 The custom-built, ball-on-flat wear simulator used in the study consisted of a stainless steel ball that rolled (range, $-5^{\circ}$ to $5^{\circ}$ ) against a HXLPE prism held on a movable X-Y table (range, -1 to $+1 \mathrm{~mm}$ ).

\section{Wear Tests and Wear Track Characterization}

Wear samples were run in a custom-built, ball-on-flat wear simulator (Fig. 1). The ball-on-flat configuration provided a nonconforming contact type, which is characteristic of knee replacements. The 2-degrees of freedom (rolling and sliding) simulator operated at a frequency of $1 \mathrm{~Hz}$ and under a 200-N static load, which generated nominal contact pressures of approximately $37 \mathrm{MPa}$. Thus, the stainless steel ball (diameter $=50 \mathrm{~mm}$; surface finish approximately $0.02 \mu \mathrm{m}$ ) rolled (range, $-5^{\circ}$ to $5^{\circ}$ ) against the HXLPE samples, which were held on a movable X-Y table (range, $-1 \mathrm{~mm}$ to $1 \mathrm{~mm}$ ). Wear experiments were carried out at room temperature in dry conditions (no lubricant or water added) for 500,000 cycles. In some cases, HXLPE prisms were artificially aged in air at $120^{\circ} \mathrm{C}$ for 36 hours [18] either before or after a 500,000 cycle-long wear experiment. In summary, the following four treatment groups were obtained after experimental conditioning: postirradiation annealed HXLPE subjected to cyclic stress, aging, and cyclic stress $(\mathrm{B} 50 \mathrm{~A}+\mathrm{C}+\mathrm{Ag}+\mathrm{C})$; postirradiation remelted HXLPE subjected to cyclic stress $(\mathrm{B} 50 \mathrm{R}+\mathrm{C})$; postirradiation remelted HXLPE subjected to aging and cyclic stress $(\mathrm{B} 50 \mathrm{R}+\mathrm{Ag}+\mathrm{C})$; and postirradiation remelted HXLPE subjected to consecutive cyclic stress, aging, and cyclic stress steps $(\mathrm{B} 50 \mathrm{R}+\mathrm{C}+\mathrm{Ag}+\mathrm{C})$. The number of samples per treatment group was one. The postirradiation annealed HXLPE was included in the study as a positive control because the material in the annealed condition is expected to oxidatively degrade and wear more on accelerated aging.

Wear tracks were characterized by means of a confocal microscope (Optical Imaging Profiler Pl $\mu$ 2300; Sensofar; Terrassa, Spain) to assess volume changes. To map the entire wear tracks, the optical imaging profiler operated in the extended topography mode in which single high-resolution three-dimensional (3-D) topography images are stitched to cover the required field. In this study, extended 3-D topography images consisted of nearly 100 single 3-D images. Mountains Map software (Digital Surf, Besançon, France) was used to obtain volume estimations and maximum depth as well as peak-to-valley-depth data for all the worn surfaces. It should be noted that volume measurements of the wear tracks are the result of a combination of plastic deformation and material loss.

\section{Compressive Fatigue Experiments}

Remelted HXLPE compression cylinders underwent uniaxial compressive fatigue experiments in an electrodynamic test instrument (ElectroPuls E1000 with WaveMatrix software; Instron, Norwood, MA, USA). Fatigue testing was performed at room temperature to a complete duration of 500,000 cycles. The fatigue experiments were carried out under load control following a sinusoidal waveform (frequency approximately $1 \mathrm{~Hz}$ ). Maximum loads were chosen so that the nominal maximum compressive stress was $-37 \mathrm{MPa}$ for the tested material, and the stress ratio ( $\mathrm{R}=$ ratio of minimum load to maximum load) was selected to be $\mathrm{R}=0.1$. For these tests, the treatment groups were: postirradiation remelted HXLPE subjected to compression fatigue $(\mathrm{B} 50 \mathrm{R}+\mathrm{F})$; postirradiation remelted HXLPE subjected to aging in air $\left(120^{\circ} \mathrm{C} ; 36\right.$ hours $)$ and 500,000 cycles of uniaxial compressive fatigue $(\mathrm{B} 50 \mathrm{R}+\mathrm{Ag}+\mathrm{F})$; and postirradiation remelted HXLPE subjected to consecutive compressive fatigue, aging, and compressive fatigue steps $(\mathrm{B} 50 \mathrm{R}+\mathrm{F}+\mathrm{Ag}+\mathrm{F})$. As for the wear tests, the number of specimens per treatment group was one.

\section{FTIR oxidation assessment}

Fourier transform infrared spectroscopy (FTIR) spectroscopy was performed following ASTM F2102 guidelines on $200-\mu \mathrm{m}$ slices microtomed from cross-sections of wear samples and longitudinal sections of the fatigued compression cylinders [1]. Generally, one section $(n=1)$ was scanned per material group, but in some cases, another section was scanned to obtain SD estimates of the data of interest. For the wear samples, spectra of both loaded and unloaded regions were recorded at $100-\mu \mathrm{m}$ increments starting from the surface. FTIR spectra of the longitudinal sections of fatigued compression cylinders were collected with depth from the surface of both regions in contact with the superior and the inferior compression plates. Spectra were recorded with an aperture size of approximately 
$100 \mu \mathrm{m}^{2}$, a resolution of $4 \mathrm{~cm}^{-1}$, and after 32 scans, using a Vertex 70 spectrometer (Bruker Corporation, Billerica, MA, USA) with a microscope accessory (IR-Plan Microscope; Model 0044-00502; Spectra Tech, Batavia, OH, USA). Oxidation indices were calculated from FTIR spectra as the area ratio of the $1650-$ to $1850-\mathrm{cm}^{-1}$ and 1330 - to $1396-\mathrm{cm}^{-1}$ absorption bands according to ASTM guidelines [1]. Additionally, crystallinity percentages were calculated to gain insight into potential aging-induced or mechanically induced crystallinity changes. Crystallinity data were obtained from FTIR spectra using equation 1 based on the areas of the crystalline and amorphous bands centered at $1897 \mathrm{~cm}^{-1}$ and $1303 \mathrm{~cm}^{-1}[5,20]$.

$\% C=\frac{\frac{A_{1897}}{A_{1303}}}{\frac{A_{1897}}{A_{1303}}+1} * 100$

The experimental design was intended to qualitatively detect potential increases in FTIR oxidation and crystallinity data resulting from cyclic stress induced by wear or by cyclic compression loading experiments of arbitrary duration. Because the number of samples was one per material group, no statistical analyses were performed. The oxidation data reported were assessed as: oxidation index $(\mathrm{OI})<1$ (low oxidation), $1<\mathrm{OI}<3$ (moderate oxidation), and OI $>3$ (high oxidation). Previous studies have correlated gradual decreases in mechanical properties of HXLPE materials because the OIs exceed these reference levels [7]. Finally, the impact of oxidative aging on the wear of remelted HXLPE was qualitatively assessed by means of wear track characterization aimed at detecting potential evidence of oxidation-induced delamination wear.

\section{Results}

Qualitatively, FTIR spectra collected from loaded and unloaded areas of wear-tested samples confirmed annealed crosslinked polyethylene reached the highest OIs $(\mathrm{OI}>3)$ in near-surface regions (Fig. 2). In particular, the highest oxidation (OI approximately 6) was registered on the very surface of the contact area. Remelted HXLPE wear samples had OIs $\leq 1$ when the material was subjected to either cyclic stress or artificial aging steps alone (Fig. 2). However, OIs almost doubled (OI approximately 2) in near-surface regions when remelted HXLPE wear samples were subjected to consecutive aging and cyclic stress steps. Moreover, oxidation was qualitatively slightly higher in the loaded area when remelted HXLPE was subjected to consecutive cyclic stress, artificial aging, and cyclic stress steps (Fig. 2). Finally, consecutive aging and cyclic stress resulted in elevated crystallinity, but cyclic stress alone only resulted in qualitatively slightly increased crystallinity in the near-surface

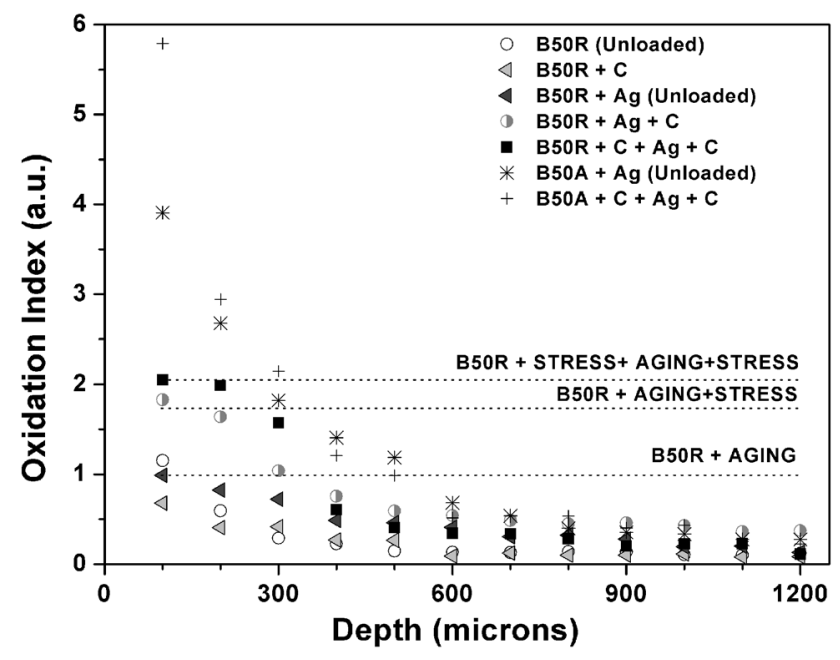

Fig. 2 The oxidation index - depth plot shows the progression of oxidation in loaded and unloaded regions of postirradiation annealed B50A and postirradiation remelted B50R HXLPE wear samples on different combinations of $0.5 \times 10^{6}$ cycles of wear testing $(\mathrm{C})$ and accelerated aging $(\mathrm{Ag})$ steps.

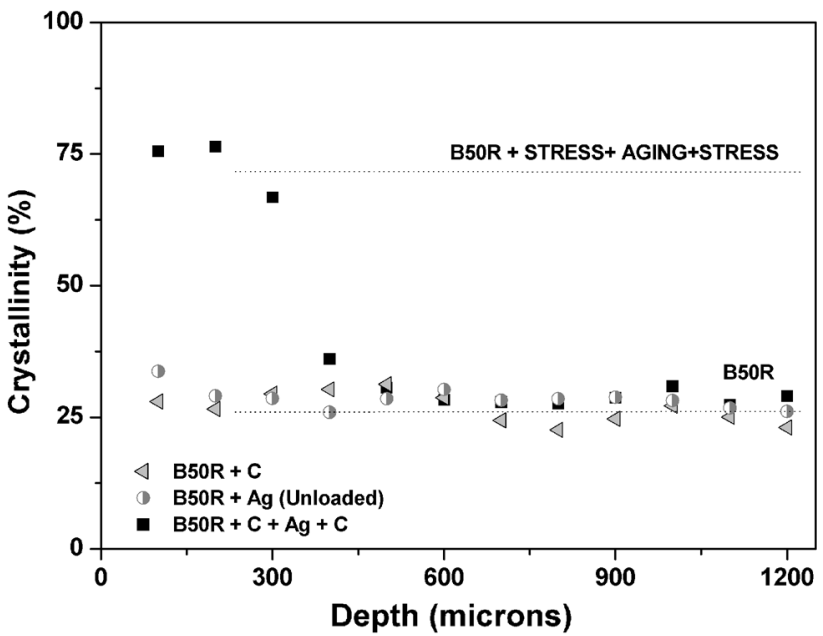

Fig. 3 The crystallinity percentage-depth plot shows the changes in crystallinity experienced by remelted HXLPE wear samples (B50R) on wear testing $(\mathrm{C})$ and accelerated aging $(\mathrm{Ag})$ steps.

(down to $600 \mu \mathrm{m}$ ) regions of the contact area compared with the crystallinity found for the bulk material (Fig. 3).

For qualitative FTIR assessments carried out on longitudinal sections of remelted HXLPE compression fatigue cylinders, the highest oxidation (OI approximately 1.5) was again registered after consecutive cyclic stress, aging, and cyclic stress steps (Fig. 4). The maximum OI was located on the very surface of the cylinder base that was in contact with the superior plate of the electromechanical instrument. Beyond $500 \mu \mathrm{m}$ in depth, OI dropped to low oxidation levels (OI approximately 0.25). Although remelted HXLPE subjected to artificial aging and subsequent fatigue steps 


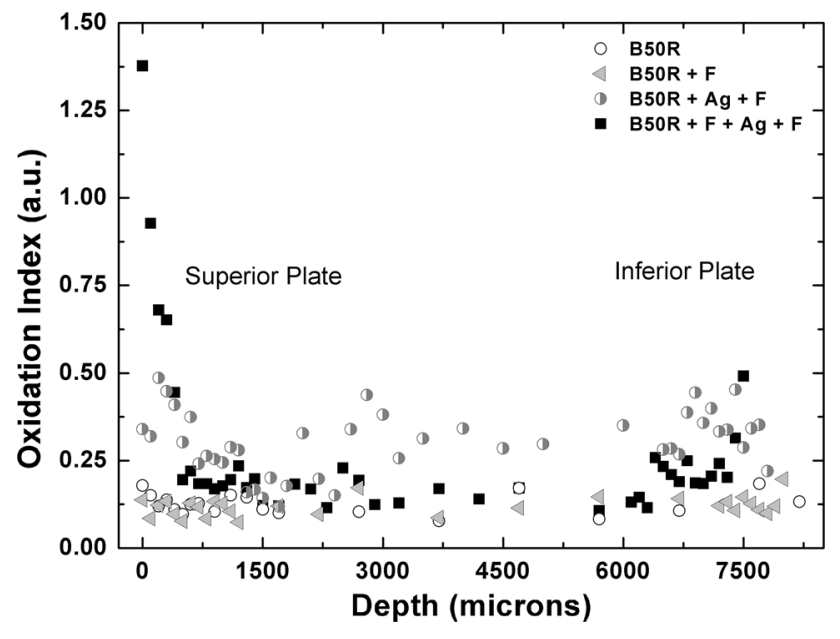

Fig. 4 The oxidation index-depth plot shows the progression of oxidation in fatigued compression cylinders of remelted HXLPE (B50R) on different combinations of $0.5 \times 10^{6}$ cycles of fatigue testing $(\mathrm{F})$ and artificial-aging $(\mathrm{Ag})$ steps.

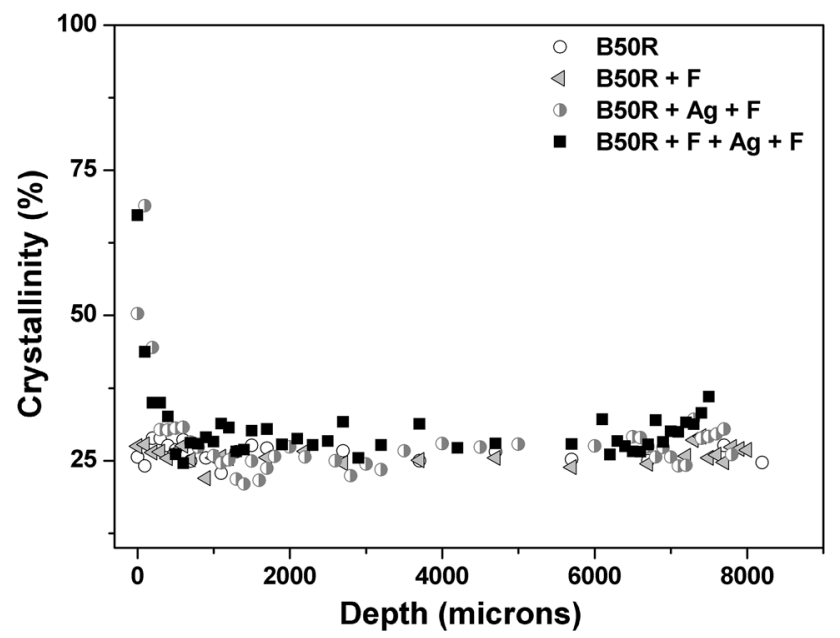

Fig. 5 The crystallinity percentage-depth plot shows the crystallinity changes in fatigued compression cylinders of remelted HXLPE (B50R) on different combinations of $0.5 \times 10^{6}$ cycles of fatigue testing $(\mathrm{F})$ and artificial-aging $(\mathrm{Ag})$ steps.

showed qualitatively higher oxidation $(\mathrm{OI} \leq 0.50)$ than its fatigued but nonaged counterpart (OI approximately 0.1 ), it did not reach the OI surface maximum of the fatigued, aged, and again fatigued, remelted HXLPE material (OI approximately 1.5 ). Regarding crystallinity, the combined effects of aging and cyclic stress were again dominant (Fig. 5).

Highly oxidized (OI $\geq 6$ ), annealed, crosslinked polyethylene was observed to delaminate after completion of consecutive cyclic stress, artificial aging, and cyclic stress steps. Thus, a considerable amount of loose polyethylene debris was observed to be transferred to the metallic ball and the wear track surroundings. Although the annealed
Table 1. Wear tracks of postirradiation stabilized HXLPEs subjected to different combinations of cyclic loading $\left(0.5 \times 10^{6}\right.$ cycles; $\left.\mathrm{C}\right)$ and accelerated aging $(\mathrm{Ag})$

\begin{tabular}{lcll}
\hline Material & $\begin{array}{l}\text { Maximum } \\
\text { depth }(\mu \mathrm{m})\end{array}$ & $\begin{array}{l}\text { Peak-to-valley } \\
\text { depth }(\mu \mathrm{m})\end{array}$ & $\begin{array}{l}\text { Volume } \\
\left(\mathrm{mm}^{3}\right)\end{array}$ \\
\hline B50R+C & 80 & 151 & 0.516 \\
B50R+C+Ag+C & 93 & 158 & 0.845 \\
B50A+C+Ag+C & 112 & 184 & 0.830 \\
\hline
\end{tabular}

HXLPE = highly crosslinked polyethylenes; B50R = electron beam irradiated $(50 \mathrm{kGy})$ and remelted; $\mathrm{B} 50 \mathrm{~A}=$ electron beam irradiated (50 kGy) and annealed.

HXLPE material exhibited the deepest wear track (maximum depth and peak-to-valley height) among the tested samples, it did not have the largest wear track volume (Table 1; Fig. 6A). Remelted HXLPE did not exhibit substantial wear except for a thin transfer film onto the metallic ball (Table 1; Fig. 6B). Even after consecutive cyclic loading, artificial aging, and cyclic loading steps, remelted HXLPE showed no evidence of delamination (Fig. 6C).

\section{Discussion}

Remelted HXLPEs have been considered the most stable among the first-generation HXLPE materials because of the lack of detectable free radicals on production. However, retrieval studies have recently reported measurable oxidation levels in remelted HXLPE explants [8, 15, 22]. The mechanisms of in vivo oxidation of remelted HXLPE implants remain unclear. Therefore, we investigated the role of cyclic loading in the oxidation, crystallinity, and wear behavior of remelted HXLPE materials. In this pilot study, we found that cyclic stress, under both wear and compression cyclic loading conditions, was able to trigger the loss of oxidative stability of remelted HXLPE and also to contribute to synergistically accelerate its progression. Regarding mechanically induced crystallinity changes, our findings are not conclusive and the effects of accelerated aging on crystallinity are much more dominant. Finally, we found no evidence of delamination wear in the case of remelted HXLPE even after consecutive cyclic stress, aging, and cyclic stress steps in coherence with oxidation levels lower than 3 .

Our study has several limitations. First, the wear and fatigue testing conditions we devised did not reproduce the physiologic loading and the in vivo environment of human joints, and their clinical wear significance is therefore limited. In particular, our custom-built wear simulator does not mimic the rotation motion and the dynamic loading characteristic of the knee. The implementation of this third- 

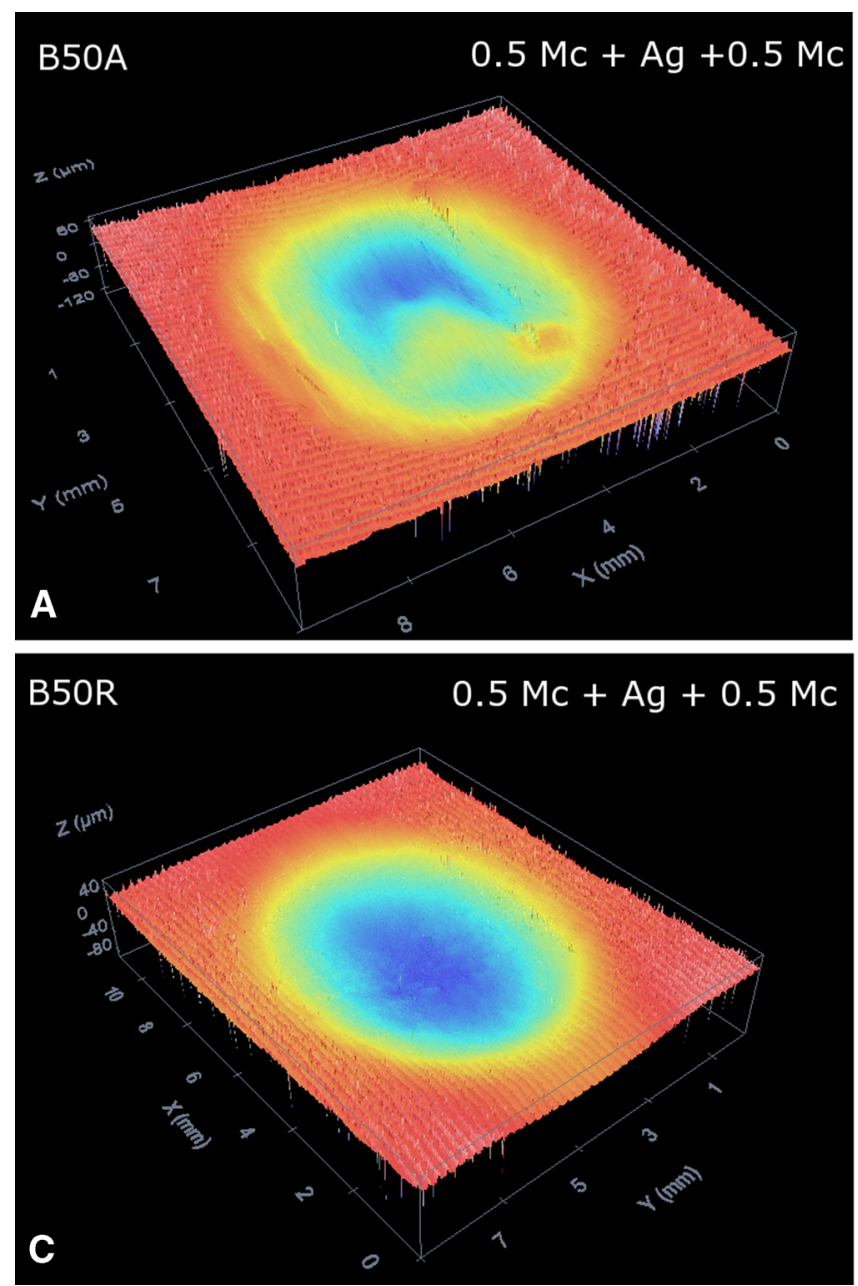

Fig. 6A-C Confocal images of wear tracks allowed the assessment of wear and plastic deformation changes in (A) annealed HXLPE subjected to cyclic loading, artificial aging, and cyclic loading;

degree of freedom and the dynamic loading might affect the oxidation of remelted HXLPE differently than the tests we conducted. Regarding the presence of in vivo fluids, we decided to perform the experiments with no biologic lubricants added to avoid potential interactions of prooxidants such as squalene in the initiation and progression of oxidation. Second, wear and fatigue testing are costly and time-consuming and, for economy of time reasons, test duration was selected to be 500,000 cycles, which is typically considered as the running-in period in standard knee wear simulation. A recent study has determined the mean activity of healthy patients with a well-functioning THA to be 2.04 million gait cycles/year in the early postimplantation period [2]. Therefore, our test duration was relatively short and a higher number of cycles could have had more of an effect on the OI and crystallinity of the bearing surface. Likewise, sample size was also limited to one in all the material groups. Thus, the findings of our study must be considered preliminary with limited clinical

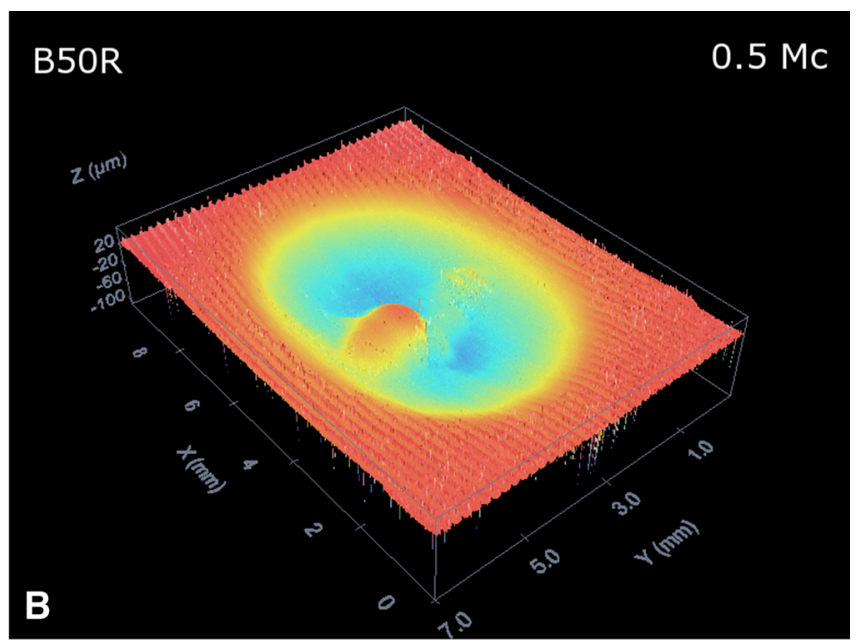

(B) remelted HXLPE on cyclic loading; and (C) remelted HXLPE on cyclic loading, aging, and cyclic loading.

significance and cautiously interpreted, especially those pertaining to no substantial differences between material groups such as no changes in oxidation levels on cyclic stress conditioning alone or similar wear performance of remelted HXLPEs regardless of the mechanical and aging treatments. However, the experimental design and the associated results may be useful in guiding treatment conditions to pursue in a more robust study. Finally, the artificial aging conditions did not reproduce the temperature $\left(37^{\circ} \mathrm{C}\right)$ and presence of body fluids characteristic of the human joint. Actually, our accelerated aging protocol represented a severe oxidative challenge [18]. Nevertheless, the in vivo environment conditions may initiate and accelerate oxidation in UHMWPE as reported by Oral and colleagues [24]. Therefore, once oxidation is initiated by prooxidants such as squalene, it could synergistically progress assisted by cyclic loading in vivo.

Our study findings suggest that cyclic loading may alter the oxidative stability of remelted HXLPE and, on 
initiation, exacerbate the progression of oxidation. Moreover, the effects of cyclic loading and artificial aging appeared to be cumulative. Although a 500,000-cycle-long wear or compression fatigue test in the reported conditions had no immediate effect on the oxidation levels of remelted HXLPE, the findings suggest that the cyclic loading may have activated the material's susceptibility to oxidation, as reflected in results obtained after subsequent aging and cyclic loading steps. In the other cases, namely remelted HXLPE subjected to aging alone, or to aging and cyclic loading, comparatively lower OIs were registered. Our results generally agree with previous retrieval studies that confirmed ex vivo stability loss and measurable oxidation levels for remelted HXLPE explants [9, 15, 16, 22, 24]. In this sense, Oral and colleagues recently demonstrated that absorbed squalene, a biological prooxidant, could initiate and accelerate oxidation in remelted crosslinked polyethylene [24]. Moreover, evidence of subtle, but measurable, increases in oxidation levels of regions exposed to physiologic loading of ethylene oxide (EtO)-sterilized, unirradiated UHMWPE retrievals have been reported [6, 14, 27]. Like with remelted HXLPE implants, EtO-sterilized implants show undetectable free radicals on production, and oxidation is not expected to occur. More retrieval studies are needed to determine the impact of potential mechanically induced (or assisted) oxidation, especially in long-term remelted HXLPE and EtO-sterilized UHMWPE explants. The mechanisms of initiation and/or progression of oxidation on cyclic stress application remain to be elucidated. In this sense, preliminary free radical studies carried out in our laboratory on wear-tested remelted HXLPE samples gave no evidence of mechanically induced free radicals, suggesting that if free radicals were originated by cyclic loading, they rapidly decayed.

With the numbers available and under our study conditions, we observed no dependence of the initiation or progression of oxidation on the loading type. Both weartested samples and fatigued compression cylinders exhibited similar oxidative behavior when subjected to consecutive cyclic loading and aging steps. However, we observed different effects on crystallinity depending on the loading type. Remelted HXLPE wear samples exhibited slightly higher near-surface crystallinity on wear testing alone, but no clear trend was registered for compression fatigue-tested remelted HXLPE cylinders. Two potential mechanisms are proposed based on the observed effects of cyclic stress in both wear and fatigue testing conditions. On the one hand, mechanically increased crystallinity in the near surface of the contact area of wear-tested remelted HXLPEs might be related to creep phenomena. Sobieraj and colleagues found that large deformation compression well beyond yield (true strain: -1.8 ) provoked increases in the melting temperature and lamellar crystal thickness, but a crystallinity decrease in postirradiation remelted HXLPE [29]. Thus, they affirmed compression-induced crystallinity degradation occurred, probably involving changes in features of both amorphous and crystalline phases of the material such as free volume and interfacial free energy. In our case, although not totally comparable, the observed crystallinity change might entail a decreased free volume or an elevated interfacial free energy, which, in turn, could facilitate oxidation to occur. On the other hand, internal stresses developed during cyclic loading might result in chain scission and, therefore, creation of free radicals that eventually would take part in the oxidation process. Insights into the oxidation potential, that is, hydroperoxide species, on cyclic loading could help ascertain the route of mechanically initiated oxidation [4].

Regarding the wear behavior of HXLPE materials, annealed HXLPE reached the highest oxidation (OI approximately 6) and, consistent with this high level of oxidation, we found the material exhibited the deepest wear track and delamination debris on the wear track surroundings. In contrast, remelted HXLPE attained comparatively lower oxidation levels $(\mathrm{OI} \leq 2)$ even after consecutive cyclic loading and aging steps. Consistently, the wear behavior of remelted HXLPE did not substantially change after cyclic loading and aging protocols. Taken together, these results are in agreement with the decreases in ultimate tensile strength and elongation-to-failure properties of shelf-aged and in vivo-oxidized, gammasterilized bearings reported by Currier and colleagues [7]. That is, once the OI approached 3, an abrupt loss of mechanical properties was registered. The effects of high oxidation levels $(\mathrm{OI} \geq 3)$ on the wear behavior of remelted HXLPE remain unknown and warrant future long-term retrieval studies.

In conclusion, our preliminary work provided evidence that cyclic loading can alter the oxidative stability of remelted HXLPE and may assist in the progression of oxidation. With the numbers available, cyclic loading and accelerated aging alone had no substantial effects on oxidation levels of remelted HXLPE. However, relatively high oxidation levels were reached on consecutive cyclic loading and artificial aging steps, indicating that both factors contribute synergistically to the oxidative degradation of the polymer. In addition, cyclic uniaxial compression appears to be sufficient to initiate and accelerate oxidation under certain conditions. The wear behavior of remelted HXLPE was not substantially affected by OIs close to 2 , but the effects of higher oxidation levels remain unknown. To definitively ascertain the effects of cyclic stress on the oxidation of HXLPE, further studies based on the present experimental approach, but accounting for statistical variability, are needed. Moreover, retrieval studies are also needed to monitor the oxidative and wear performances of 
remelted HXLPE and other UHMWPE formulations implants [28], especially in the long term.

Acknowledgments We thank Javier Sánchez and Carlos Marzo for technical assistance in wear simulator and compressive fatigue experiments, respectively. Also, the assistance of María Dolores Domínguez, Isaías Fernández, and Natalia Fernández with FTIR characterization is acknowledged.

\section{References}

1. ASTM International. ASTM F2102-06. Standard Guide for Evaluating the Extent of Oxidation in Ultra-high Molecular Weight Polyethylene Fabricated Forms Intended for Surgical Implants. West Conshohocken, PA, USA: ASTM International; 2006.

2. Battenberg AK, Hopkins JS, Kupiec AD, Schmalzried TP. The 2012 Frank Stinchfield Award: Decreasing patient activity with aging: implications for crosslinked polyethylene wear. Clin Orthop Relat Res. 2013;471:386-392.

3. Collier JP, Sutula LC, Currier BH, Currier JH, Wooding RE, Williams IR, Farber KB, Mayor MB. Overview of polyethylene as a bearing material: comparison of sterilization methods. Clin Orthop Relat Res. 1996;333:76-86.

4. Costa L, Bracco P, Brach del Prever EM, Kurtz SM, Gallinaro P. Oxidation and oxidation potential in contemporary packaging for polyethylene total joint replacement components. J Biomed Mater Res B Appl Biomater. 2006;78:20-26.

5. Costa L, Jacobson K, Bracco P, Brach del Prever EM. Oxidation of orthopaedic UHMWPE. Biomaterials. 2002;23:1613-1624.

6. Costa L, Luda MP, Trossarelli L, Brach del Prever EM, Crova M, Gallinaro P. Oxidation in orthopaedic UHMWPE sterilized by gamma-radiation and ethylene oxide. Biomaterials. 1998;19: 659-668.

7. Currier BH, Currier JH, Mayor MB, Lyford KA, Van Citters DW, Collier JP. In vivo oxidation of gamma-barrier-sterilized ultrahigh-molecular-weight polyethylene bearings. J Arthroplasty. 2007;22:721-731.

8. Currier BH, Van Citters DW, Currier JH, Carlson EM, Tibbo ME, Collier JP. In vivo oxidation in retrieved highly crosslinked tibial inserts. J Biomed Mater Res B Appl Biomater. 2013;101: 441-448.

9. Currier BH, Van Citters DW, Currier JH, Collier JP. In vivo oxidation in remelted highly cross-linked retrievals. $J$ Bone Joint Surg Am. 2010;92:2409-2418.

10. Dumbleton JH, Wang A, Sutton K, Manley MT. Highly crosslinked and annealed UHMWPE. In: Kurtz SM, ed. UHMWPE Biomaterials Handbook. $2^{\text {nd }}$ ed. Boston, MA, USA: Academic Press; 2009:205-219.

11. Kurtz SM, Hozack W, Turner J, Purtill J, MacDonald D, Sharkey P, Parvizi J, Manley M, Rothman R. Mechanical properties of retrieved highly cross-linked crossfire liners after short-term implantation. J Arthroplasty. 2005;20:840-849.

12. Kurtz SM, Hozack WJ, Purtill JJ, Marcolongo M, Kraay MJ, Goldberg VM, Sharkey PF, Parvizi J, Rimnac CM, Edidin AA. 2006 Otto Aufranc Award Paper: significance of in vivo degradation for polyethylene in total hip arthroplasty. Clin Orthop Relat Res. 2006;453:47-57.

13. Kurtz SM, Manley M, Wang A, Taylor S, Dumbleton J. Comparison of the properties of annealed crosslinked (Crossfire) and conventional polyethylene as hip bearing materials. Bull Hosp Jt Dis. 2002;61:17-26.

14. MacDonald D, Hanzlik J, Sharkey P, Parvizi J, Kurtz SM. In vivo oxidation and surface damage in retrieved ethylene oxide- sterilized total knee arthroplasties. Clin Orthop Relat Res. 2012;470:1826-1833.

15. MacDonald D, Sakona A, Ianuzzi A, Rimnac CM, Kurtz SM. Do first-generation highly crosslinked polyethylenes oxidize in vivo? Clin Orthop Relat Res. 2011;469:2278-2285.

16. MacDonald DW, Higgs G, Parvizi J, Klein G, Hartzband M, Levine H, Kraay M, Rimnac CM, Kurtz SM. Oxidative properties and surface damage mechanisms of remelted highly crosslinked polyethylenes in total knee arthroplasty. Int Orthop. 2013;37: 611-615.

17. McKellop H, Shen FW, Lu B, Campbell P, Salovey R. Development of an extremely wear-resistant ultra high molecular weight polyethylene for total hip replacements. J Orthop Res. 1999;17:157-167.

18. Medel F, Gomez-Barrena E, Garcia-Alvarez F, Rios R, Gracia-Villa L, Puertolas JA. Fractography evolution in accelerated aging of UHMWPE after gamma irradiation in air. Biomaterials. 2004;25:9-21.

19. Medel FJ, Pena P, Cegonino J, Gomez-Barrena E, Puertolas JA. Comparative fatigue behavior and toughness of remelted and annealed highly crosslinked polyethylenes. J Biomed Mater Res B Appl Biomater. 2007;83:380-390.

20. Medel FJ, Rimnac CM, Kurtz SM. On the assessment of oxidative and microstructural changes after in vivo degradation of historical UHMWPE knee components by means of vibrational spectroscopies and nanoindentation. J Biomed Mater Res A. 2009;89:530-538.

21. Muratoglu OK, Bragdon CR, O'Connor DO, Jasty M, Harris WH, Gul R, McGarry F. Unified wear model for highly crosslinked ultra-high molecular weight polyethylenes (UHMWPE). Biomaterials. 1999;20:1463-1470.

22. Muratoglu OK, Wannomae KK, Rowell SL, Micheli BR, Malchau H. Ex vivo stability loss of irradiated and melted ultrahigh molecular weight polyethylene. J Bone Joint Surg Am. 2010;92:2809-2816.

23. Oonishi H, Clarke IC, Masuda S, Amino H. Study of retrieved acetabular sockets made from high-dose, cross-linked polyethylene. J Arthroplasty. 2001;16:129-133.

24. Oral E, Ghali BW, Neils A, Muratoglu OK. A new mechanism of oxidation in ultrahigh molecular weight polyethylene caused by squalene absorption. J Biomed Mater Res B Appl Biomater. 2012;100:742-751.

25. Oral E, Malhi AS, Muratoglu OK. Mechanisms of decrease in fatigue crack propagation resistance in irradiated and melted UHMWPE. Biomaterials. 2006;27:917-925.

26. Premnath V, Harris WH, Jasty M, Merrill EW. Gamma sterilization of UHMWPE articular implants: an analysis of the oxidation problem. Ultra high molecular weight poly ethylene. Biomaterials. 1996;17:1741-1753.

27. Regis M, Bracco P, Giorgini L, Fusi S, Dalla Pria P, Costa L, Schmid C. Correlation between in vivo stresses and oxidation of UHMWPE in total hip arthroplasty. J Mater Sci Mater Med. 2014;25:2185-2192.

28. Rios R, Puertolas JA, Martinez-Nogues V, Martinez-Morlanes MJ, Pascual FJ, Cegonino J, Medel FJ. Mechanical behavior, microstructure and thermooxidation properties of sequentially crosslinked ultrahigh molecular weight polyethylenes. J Appl Polym Sci. 2013;129:2518-2526.

29. Sobieraj MC, Kurtz SM, Rimnac CM. Large deformation compression induced crystallinity degradation of conventional and highly crosslinked UHMWPEs. Biomaterials. 2005;26: 6430-6439.

30. Sobieraj MC, Rimnac CM. Ultra high molecular weight polyethylene: mechanics, morphology, and clinical behavior. $J$ Mech Behav Biomed Mater. 2009;2:433-443. 